\title{
Global advocacy for controlling the tobacco industry
}

\section{A tobacco-free world is attainable - if we are prepared to work for it}

$\mathrm{R}$ eaders of the Medical Journal of Australia might be forgiven for assuming that the global impact of the tobacco industry has been greatly reduced. Australia is a world leader in tobacco control, based on its longstanding commitment to effective policies, and prevalence rates are declining rapidly. Globally, however, $30 \%$ of men and $6 \%$ of women still smoke. Further, projections suggest the internationally agreed target of a $30 \%$ reduction in smoking rates (base year: 2010) by 2025 , established as part of the World Health Organization's global non-communicable disease action plan, will not be achieved. ${ }^{1}$

\section{"The goal of a tobacco-free world is socially acceptable, technically feasible and could easily become politically practical"}

Tobacco is a uniquely harmful product; two out of three smokers' deaths result from their tobacco use, with a loss of an average 10 years of life. ${ }^{2}$ In the decade since the landmark WHO Framework Convention on Tobacco Control $(\mathrm{FCTC})^{3}$ was adopted, around 50 million people, mostly men living in poorer countries, have died from using tobacco, and Big Tobacco continues to be very profitable.

The FCTC is a major advance in global tobacco control, although most countries have yet to meet their obligations under the convention. Most need to speed up the implementation of key components of the treaty: increased taxation, complete bans on tobacco advertising, promotion and sponsorship, and guarantees of smokefree environments. Countries that have yet to ratify the FCTC, especially those where the tobacco industry is entrenched, ranging from Indonesia to the United States, should do so urgently. The FCTC alone, however, will not be enough to achieve a tobacco-free world, and will not stop the tobacco industry actively recruiting new smokers, especially women, a largely untapped growth market.

\section{Time for action}

Robert Beaglehole

Ruth Bonita MPH, PhD, ONZM

University of Auckland, Auckland, NZ.

r.beaglehole@ auckland.ac.nz

doi: 10.5694/mjal5.00324

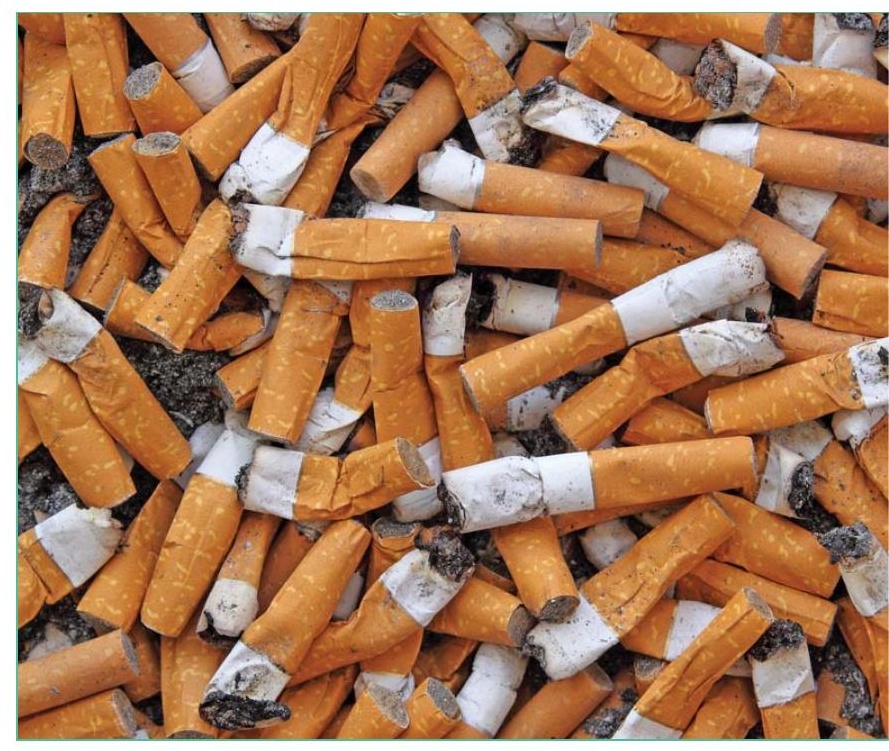

The cause of the tobacco pandemic is the tobacco industry - lethal but still lawful — and its predatory efforts to maintain profits by exploiting markets in middleand low-income countries. ${ }^{5}$ With its vast resources, the industry undermines and distorts tobacco policy in many countries. Some of its cynical efforts, however, have been countered in several high-income countries; for example, by plain packaging legislation in Australia, ${ }^{7}$ with similar legislation in Ireland and the United Kingdom following in March this year. ${ }^{8}$

Achieving a tobacco-free world by 2040 will require concerted and coordinated action at global, regional and national levels, especially in large countries such as China, where one in three of the world's smokers lives. Although there is progress, the very close relationship between the tobacco industry and the Chinese government needs to be broken. ${ }^{6}$

Several countries have set their sights on essentially tobacco-free societies by 2025 (New Zealand ${ }^{9}$ and Pacific countries $^{10}$ ) or later (Finland ${ }^{11}$ and Scotland ${ }^{12}$ ). These countries should be seen as models for regional and global efforts to achieve a tobacco-free world. Australia, for one, should also set a goal for reducing the prevalence of tobacco use to less than $5 \%$ by 2025 . A strong development case can also be made for greater leadership from the United Nations in support of the WHO and its goal of a tobacco-free world by 2040. As tobacco is an impediment to human development, it would be appropriate for the post-2015 Sustainable Development Goals currently being discussed by the UN to include a strong tobacco control target, building on the work of the FCTC. The FCTC itself 
could be usefully amended to include a target date for phasing out the sale of commercial tobacco products.

\section{Progress is possible - but needs investment}

There are no serious downsides to adopting an ambitious goal for reducing tobacco use, as long as it does not deflect attention from the accelerated implementation of the FCTC. Indeed, focusing on tobacco has a multitude of benefits: it will support calls for improving health systems, make universal health coverage more attainable, and reduce the damage done to people throughout their lives. Ambitious goals have been instrumental in rapid improvements in other areas of public health, such as reducing the mortality of childhood diseases and HIV/ AIDS. These positive trends, however, have required the investment of resources. Development agencies should extend the scope of their activities to supporting national tobacco control efforts, building on the contributions of Bloomberg Philanthropies and the Bill and Melinda Gates Foundation. Finally, the ability of countries to promote health, including through tobacco control policies, must be protected from the so-called "free" trade agreements currently under discussion.

The goal of a tobacco-free world is socially acceptable, technically feasible and could easily become politically practical. Current global anti-tobacco strategies are clearly insufficient. National and international leadership is urgently needed to counter the burdens on health and human development caused by the tobacco industry. In Australia, the priority is continuing increases in the taxation of tobacco products beyond the current 4-year cycle, increased investment in mass media campaigns, and actions targeted at vulnerable groups, including Aboriginal Australians and people with mental health issues. All Australians, including readers of this Journal, should further pursue their important advocacy role at home and abroad.

Competing interests: No relevant disclosures.

Provenance: Commissioned; externally peer reviewed.

References are available online at www.mja.com.au.
1 Bilano V, Gilmour S, Moffiet T, et al. Global trends and projections for tobacco use, 1990-2025: an analysis of smoking indicators from the WHO Comprehensive Information Systems for Tobacco Control. Lancet 2015; 385: 966-976.

2 Banks E, Joshy G, Weber MF, et al. Tobacco smoking and allcause mortality in a large Australian cohort study: findings from a mature epidemic with current low smoking prevalence. BMC Med 2015; 13: 38.

3 World Health Organization. WHO Framework Convention on Tobacco Control. Geneva: WHO, 2003.

4 Beaglehole R, Bonita R, Yach D, et al. A tobacco-free world: a call to action to phase out the sale of tobacco products by 2040. Lancet 2015; 385: 1010-1018.

5 Gilmore AB, Fooks G, Drope J, et al. Exposing and addressing tobacco industry conduct in low-income and middle-income countries. Lancet 2015; 385: 1029-1043.

6 Yang G, Wang Y, Wu Y, et al. The road to effective tobacco control in China. Lancet 2015; 385: 1019-1028.

7 Chapman S, Freeman B. Removing the emperor's clothes. Australia and tobacco plain packaging. Sydney: Sydney University Press, 2014.

8 Canadian Cancer Society. Plain packaging - overview [media release]. 10 Mar 2015. https://www.cancer.ca/ /media/cancer.
ca/CW/for\%20media/Media\%20releases/2015/plain-

packaging-overview.pdf (accessed Apr 2015).

9 New Zealand Government. Government final response to the report of the Mãori Affairs Committee on its Inquiry into the tobacco industry in Aotearoa and the consequences of tobacco use for Mãori, presented to the House of Representatives in accordance with Standing Order 248 (J.1). 2011. http://smokefree.org.nz/sites/default/files/2.\%20 Govt\%20Final\%20Response\%20to\%20Maori\%20Afairs\%20 Select\%20Committee\%20report\%20-\%20Mar\%202011.pdf (accessed Mar 2015).

10 World Health Organization, Western Pacific Region. Tobacco free Pacific 2025. [website: 2015]. http://www.wpro.who.int/ southpacific/programmes/healthy_communities/tobacco/ page/en (accessed Mar 2015).

11 Finland Ministry of Social Affairs and Health. MSAH oversees tobacco control in Finland. [website: 2013]. http://www.stm.fi/ en/welfare/substance_abuse/tobacco (accessed Mar 2015).

12 The Scottish Government. Creating a tobacco-free generation. A tobacco control strategy for Scotland. Edinburgh: The Scottish Government; 2013. http://www.gov.scot/ Publications/2013/03/3766 (accessed Mar 2015). 